\title{
Needle-knife deroofing of a symptomatic type III choledochal cyst
}

An 11-year-old patient was referred to our endoscopy unit following two bouts of acute pancreatitis of unclear cause. Because autoimmune or toxic causes were ruled out and mutation analysis for cystic fibrosis transmembrane regulator and serine protease inhibitors, Kazal type 1 , was unrevealing, cross-sectional imaging by magnetic resonance imaging (MRI) (\$ Fig.1) and a subsequent endoscopic ultrasound (EUS) were performed, both showing a cystic structure at the distal common bile duct (CBD) ( Fig. 2 , arrow). It was stipulated that local compression of a choledochal cyst could be directly causing the recurrent episodes of acute pancreatitis. The patient therefore consented to undergo endoscopic retrograde cholangiopancreatograpy (ERCP) with sphincterotomy. ERCP revealed a cystic, pre-papillary contrast opacification, findings compatible with a Todani type III choledochocele ( $\mathbf{F i g . 3}$ ). Following sphincterotomy, insufficient drainage was achieved because the cystic juxtapapillary lesion remained unchanged ( Fig.4). Subsequently, a needleknife-assisted technique was used (NeedleCut3V, Olympus Medical Systems, Tokyo, Japan), which achieved a successful cystotomy and complete drainage of the choledochal cyst ( $\triangleright$ Video 1) [1]. One month later at endoscopic follow-up, resolution of the choledochocele was seen ( Fig. 5).

Described for the first time in 1977, the Todani classification is used for describing the various configurations of choledochal cysts, varying from simple segmental bile duct dilatation (type I) to overt Caroli's disease (type V) [2]. Type III choledochal cysts are characterized by a cystic malformation of the distal $\mathrm{CBD}$, typically extending into the duodenal wall, with simultaneous drainage of the $C B D$ and pancreatic duct into the cyst. This increases intralesional pres-

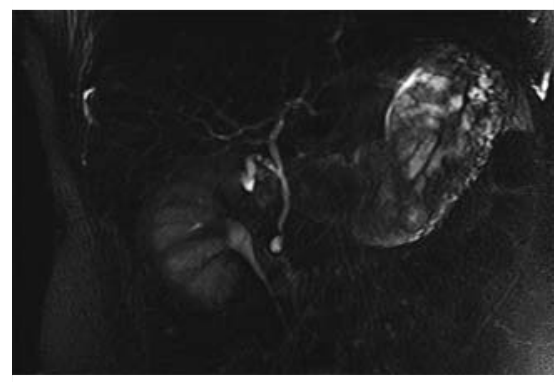

- Fig. 1 Magnetic resonance imaging, T2 RARE (rapid acquisition with relaxation enhancement) sequence, identifying a pre-papillary cystic lesion.

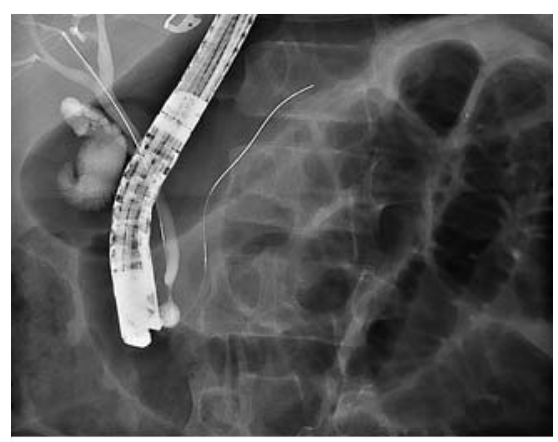

$\checkmark$ Fig. 3 Fluoroscopic image during ERCP using a double wire technique, showing a segmental dilatation of the distal common bile duct, with findings compatible with a Todani type III choledochal cyst.

sure, which may give rise to cholangitis and pancreatitis by inducing reflux of pancreatobiliary fluids [3]. Unique to type III cysts, treatment typically consists of a simple sphincterotomy. However, our case illustrates that when sphincterotomy fails, needle-knife-assisted cystotomy can provide sufficient drainage in patients with type III choledochal cysts. After 3 years of follow-up, the patient has remained asymptomatic.

Endoscopy_UCTN_Code_TTT_1AR_2AK

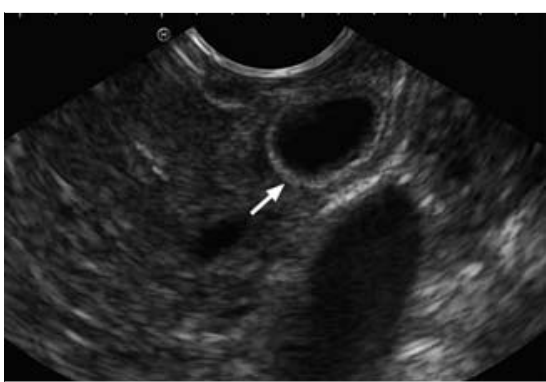

- Fig. 2 Endoscopic ultrasound confirmed a hypoechogenic, cystic lesion at the distal common bile duct, although the exact relation to the bile duct remained unclear.

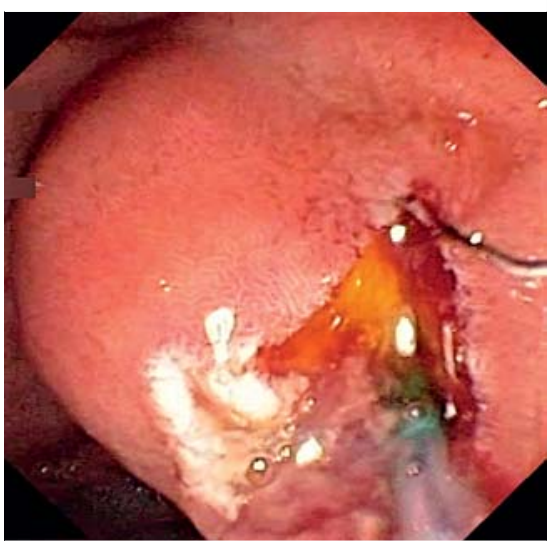

-Fig. 4 Endoscopic image revealing a bulging, juxtapapillary choledochal cyst, which remained unchanged despite successful sphincterotomy.

Competing interests

None

The authors

Giuseppe Vanella ${ }^{1,2}$, Michiel Bronswijk ${ }^{1}$, Schalk van der Merwe ${ }^{1}$

1 Department of Gastroenterology and Hepatology, University Hospitals Leuven, KU Leuven, Belgium

2 Endoscopy Unit, Sant'Andrea Hospital, Sapienza University of Rome, Italy 


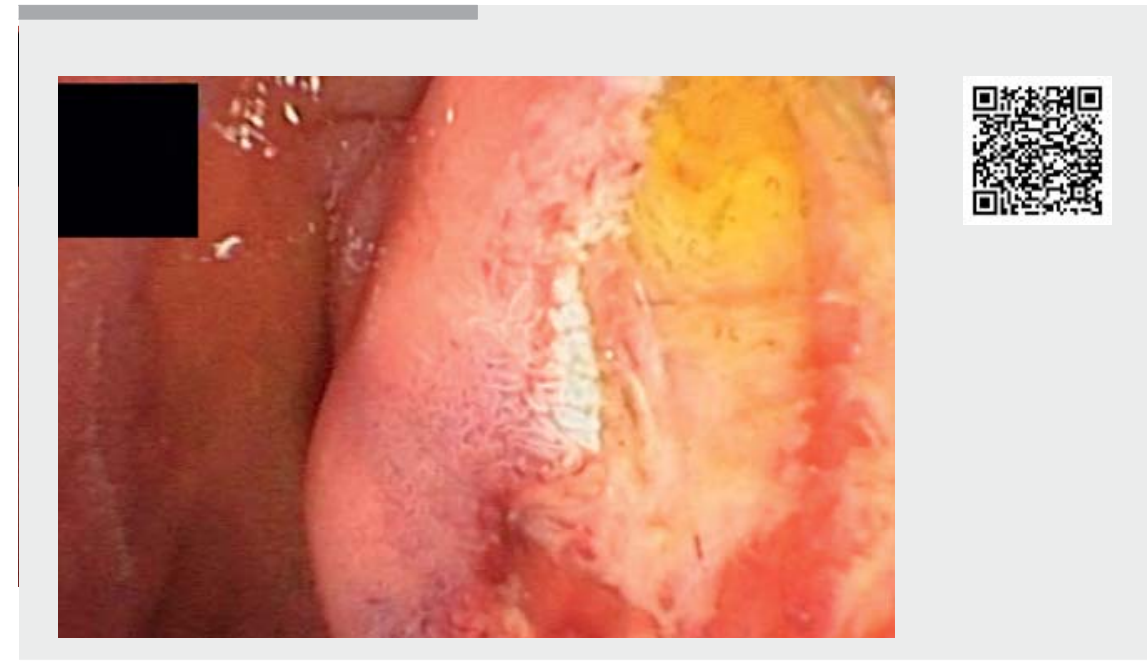

Video 1 Endoscopic treatment of a Todani type III choledochal cyst by needle-knifeassisted deroofing.

\section{Corresponding author}

\section{Michiel Bronswijk}

Herestraat 49, 3000 Leuven, Belgium

mjh.bronswijk@gmail.com

Fax: +32473886089

\section{References}

[1] Mangiavillano B, Parodi A, Conio M. Endoscopic ultrasound-guided ERCP in the treatment of a Todani type-III cyst causing acute necrotizing pancreatitis. Endoscopy 2016; 48 (Suppl. 01): E44

[2] Todani T, Watanabe Y, Narusue M et al. Congenital bile duct cysts: classification, operative procedures, and review of thirty-

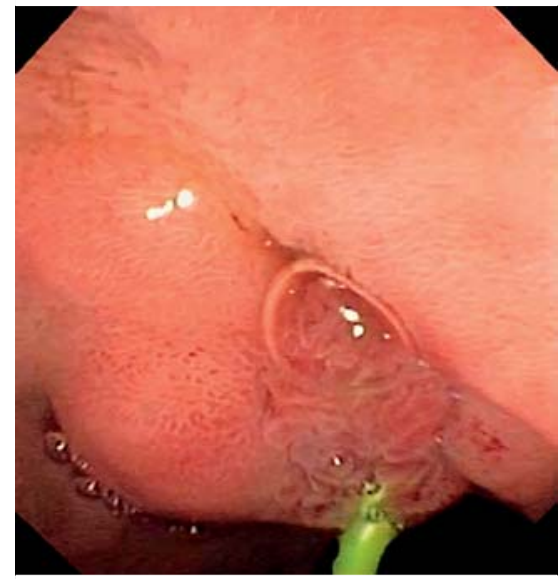

Fig. 5 Endoscopic image after 1 month, showing almost complete resolution of the intraluminal bulging with only mild residual scarring. The pancreatic stent was extracted by snare, after which the patient remained free of any recurrent episodes of pancreatitis.

\section{ENDOSCOPY E-VIDEOS}

https:/|eref.thieme.de/e-videos

[3] Jablónska B. Biliary cysts: etiology, diagnosis and management. World J Gastroenterol 2012; 18: 4801-4810

\section{Bibliography}

DOI https://doi.org/10.1055/a-1067-4271

Published online: 9.12.2019

Endoscopy 2020; 52: E191-E192

(c) Georg Thieme Verlag KG

Stuttgart · New York

ISSN 0013-726X 